\title{
Effect of Carbon Dioxide on the Degradation of Chemical Warfare Agent Simulant in the Presence of Zr Metal Organic Framework MOF-808
}

Anna M. Plonka, ${ }^{a}$ Tyler G. Grissom, ${ }^{\mathrm{b}}$ Djamaladdin G. Musaev, ${ }^{\mathrm{c}, \mathrm{d}}$ Alex Balboa, ${ }^{\mathrm{e}}$ Wesley O. Gordon, ${ }^{\mathrm{e}}$ Daniel L. Collins-Wildman, ${ }^{\mathrm{d}}$ Sanjit K. Ghose, ${ }^{\mathrm{f}}$ Yiyao Tian, ${ }^{\mathrm{a}}$ Amani M. Ebrahim, ${ }^{\mathrm{a}}$ Mark B. Mitchell,, ${ }^{\mathrm{g}}$ Craig L. Hill, ${ }^{\mathrm{d}}$ John R. Morris, ${ }^{\mathrm{b}}$ Anatoly I. Frenkel ${ }^{\mathrm{a}, \mathrm{h},{ }^{*}}$

${ }^{a}$ Department of Materials Science and Chemical Engineering, Stony Brook University, Stony Brook, NY 11794, USA

${ }^{\mathrm{b}}$ Department of Chemistry, Virginia Tech, Blacksburg, VA 24061, USA

${ }^{\mathrm{c}}$ Cherry L. Emerson Center for Scientific Computation, Emory University, Atlanta, GA 30322, USA

${ }^{d}$ Department of Chemistry, Emory University, Atlanta, GA 30322, USA

${ }^{\mathrm{e}}$ U.S. Army CCDC Chemical Biological Center, APG, MD 21010, USA

${ }^{f}$ National Synchrotron Light Source II, Brookhaven National Laboratory, PO Box 5000, Upton, NY 11973, USA

g Department of Chemistry, Kennesaw State University, Kennesaw, GA 30144, USA

${ }^{\mathrm{h}}$ Division of Chemistry, Brookhaven National Laboratory, Upton, NY 11794, USA

\section{Supporting Information}




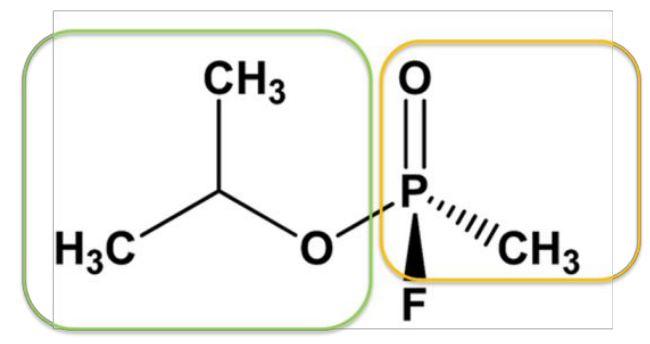

SARIN

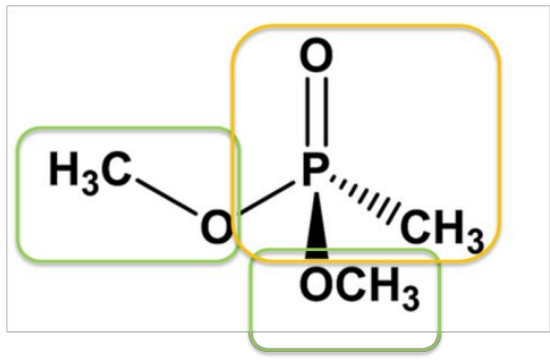

DMMP

Figure S1: Structures of the G-type chemical warfare agent, Sarin (GB), and the simulant, dimethyl methyl phosphonate (DMMP).

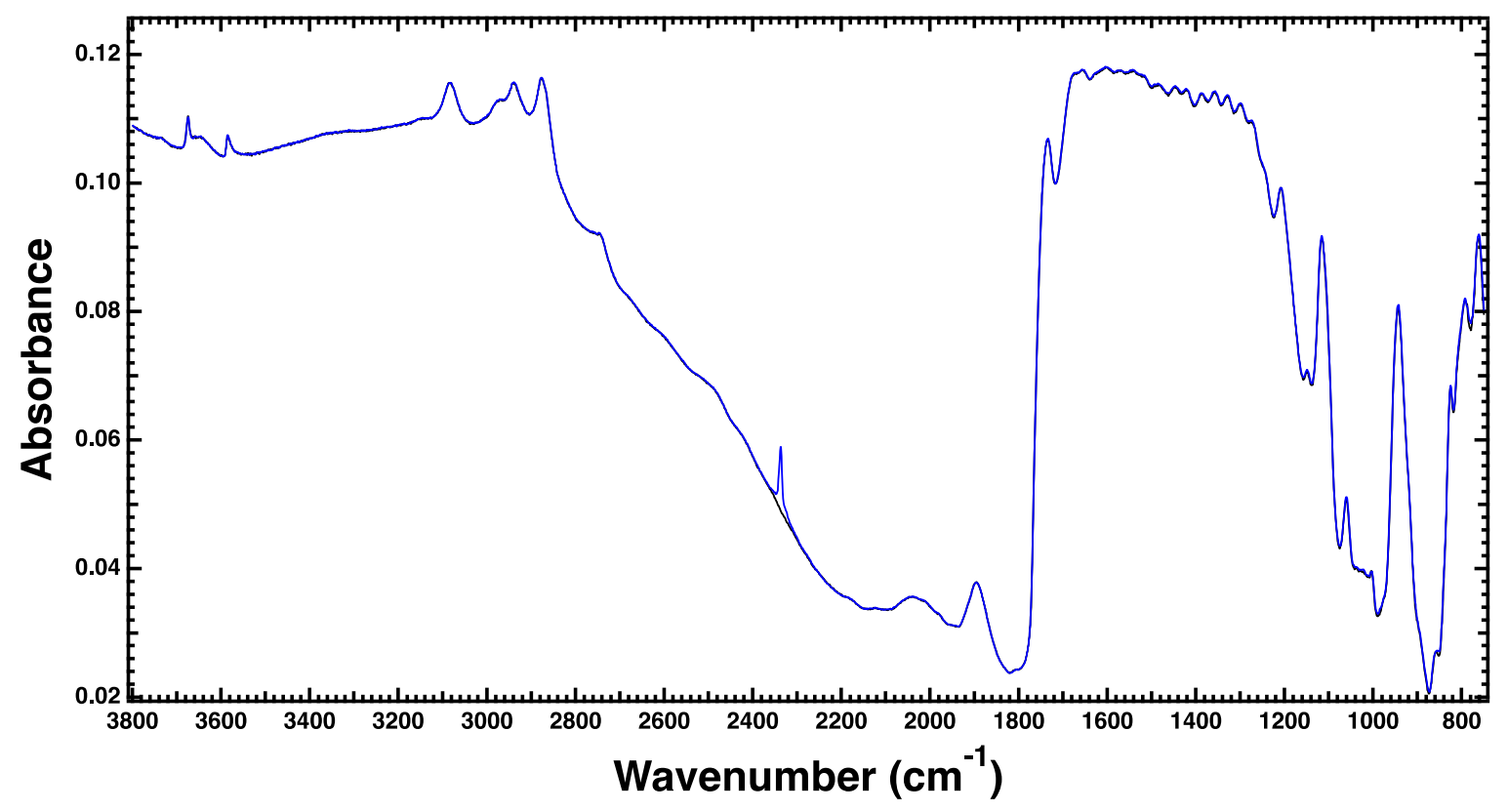

Figure S2: IR spectra of (black) clean MOF-808 under vacuum following $448 \mathrm{~K}$ activation and (blue) MOF-808 during 1.5 Torr of $\mathrm{CO}_{2}$ exposure at $303 \mathrm{~K}$. Gas phase $\mathrm{CO}_{2}$ features have been subtracted out. 


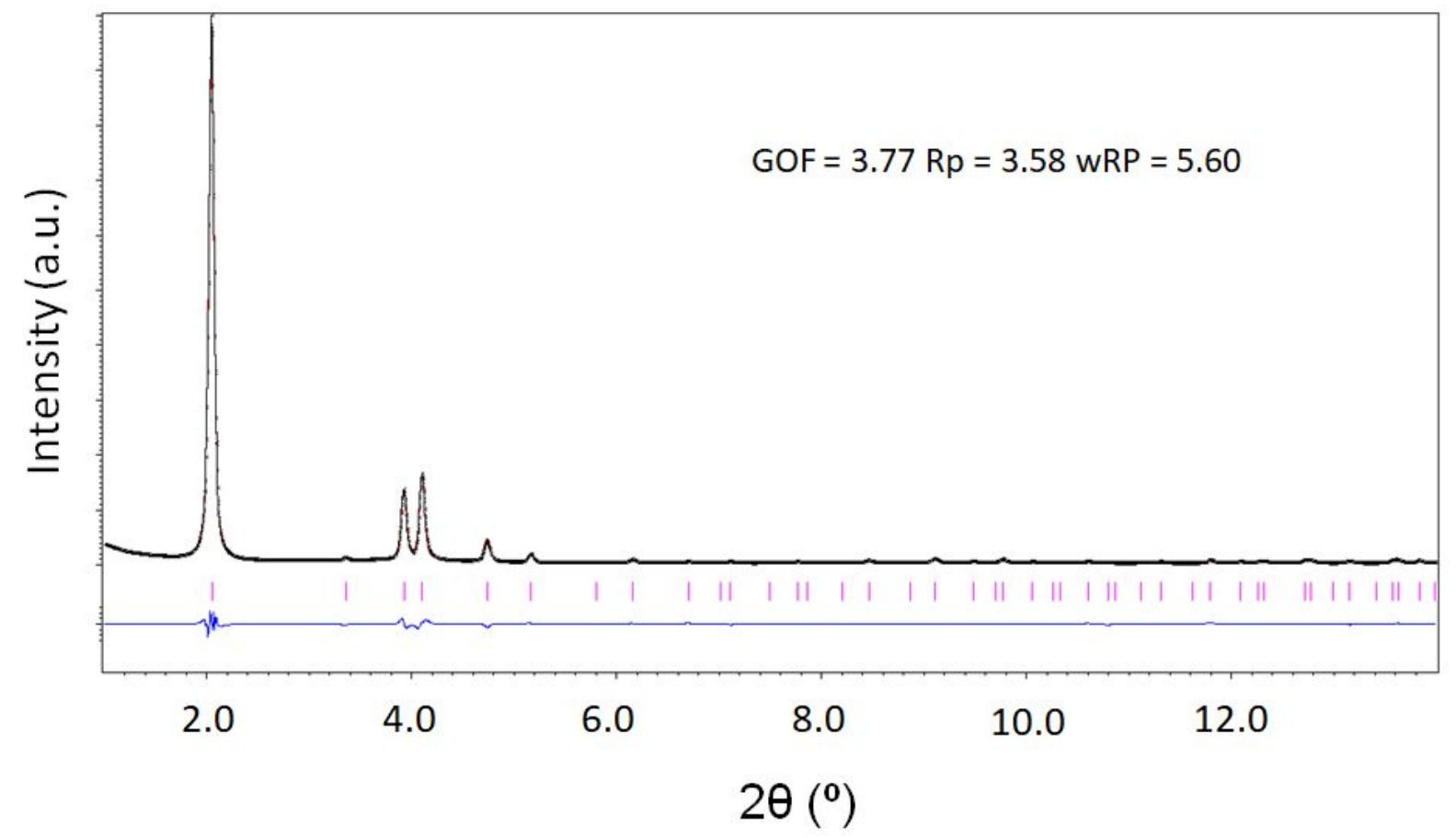

Figure S3. Rietveld refinement of the activated MOF-808. Black curve shows observed data, red calculated, blue - difference curve, magenta - peak position.

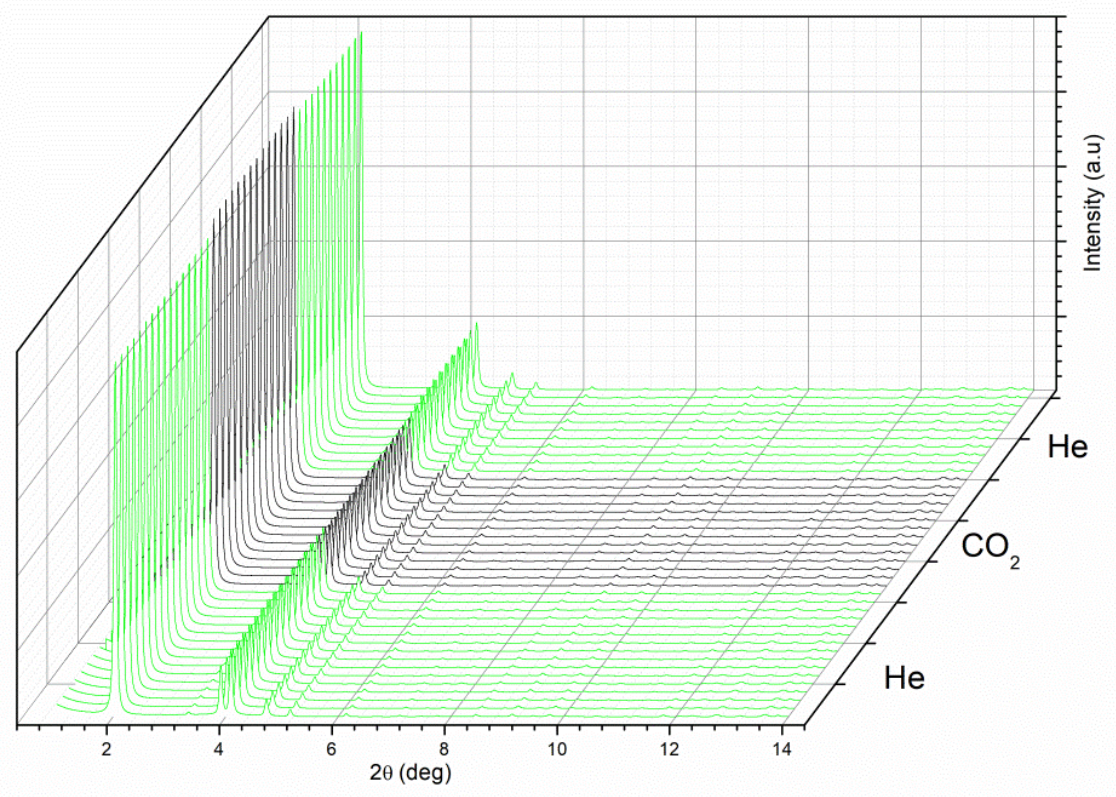

Figure S4. In situ time resolved PXRD data collected during $\mathrm{CO}_{2}$ adsorption/desorption 


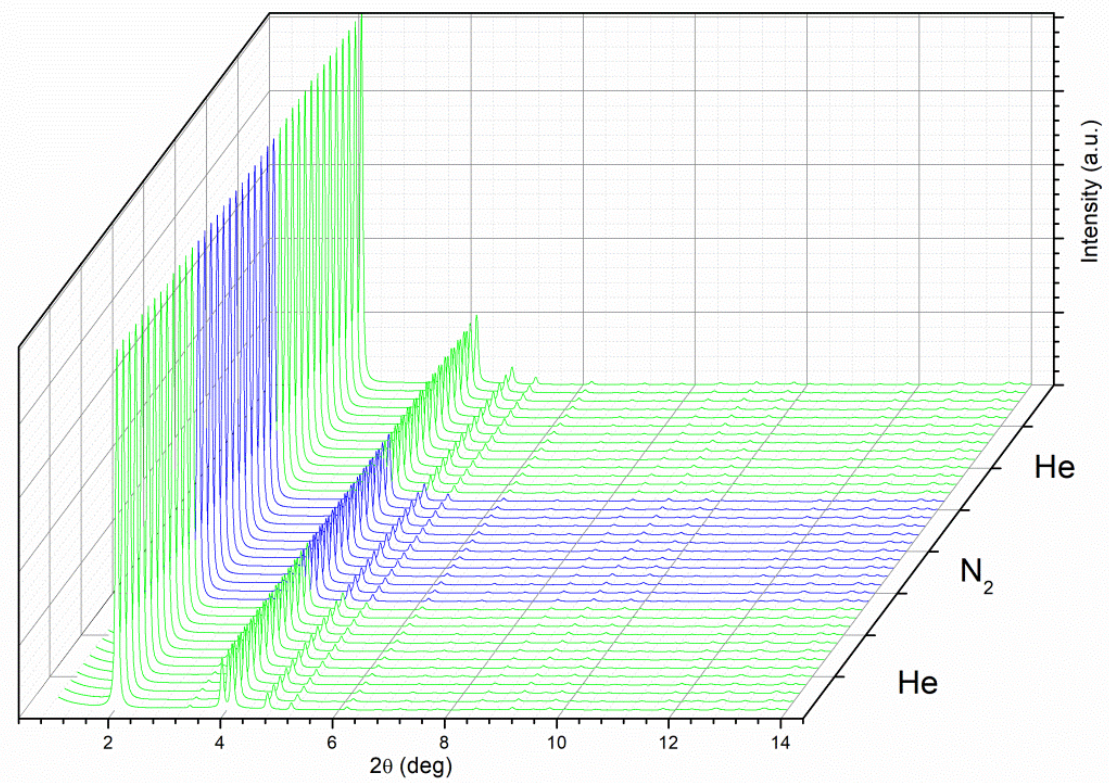

Figure S5. In situ time resolved PXRD data collected during $\mathrm{N}_{2}$ adsorption/desorption

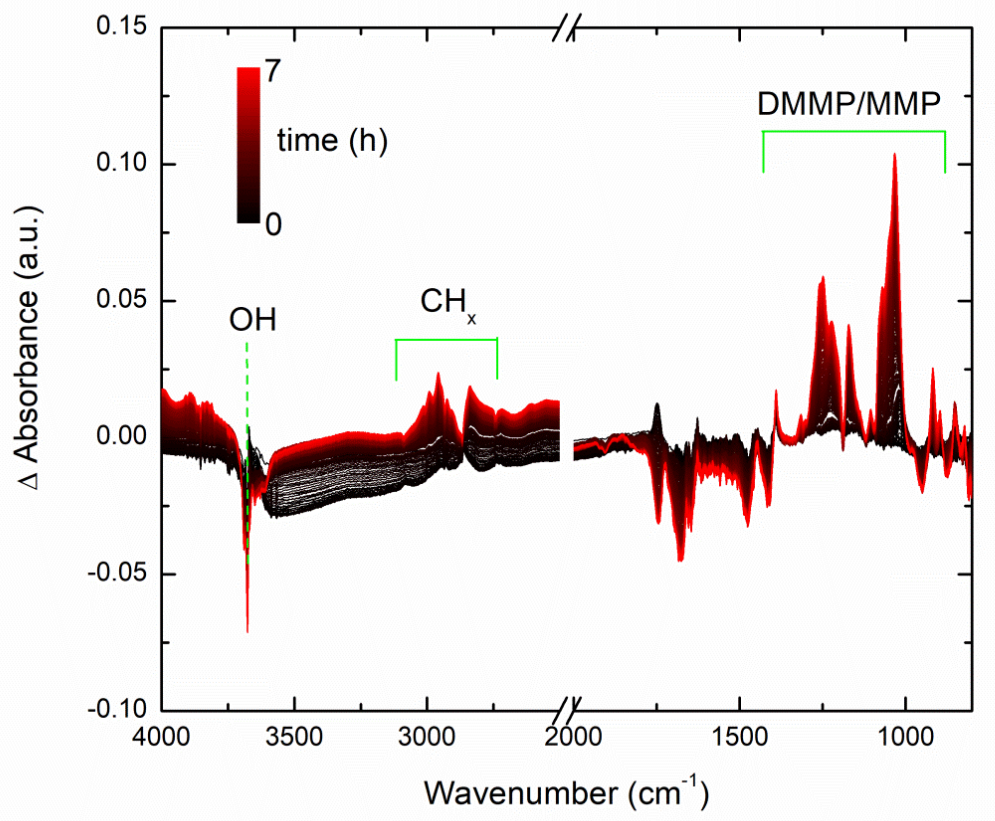

Figure S6. In situ time resolved DRIFTS data collected during DMMP dosing with $\mathrm{N}_{2}$ as a carrier gas. 


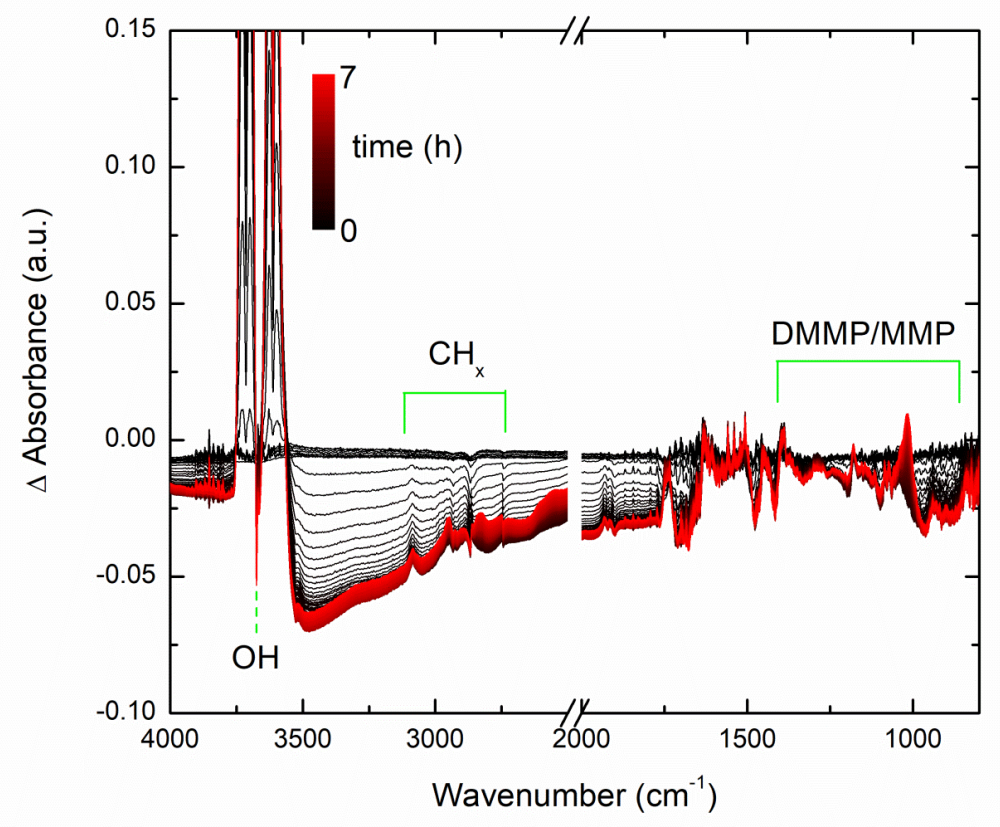

Figure S7. In situ time resolved DRIFTS data collected during DMMP dosing with $\mathrm{CO}_{2}$ as a carrier gas.

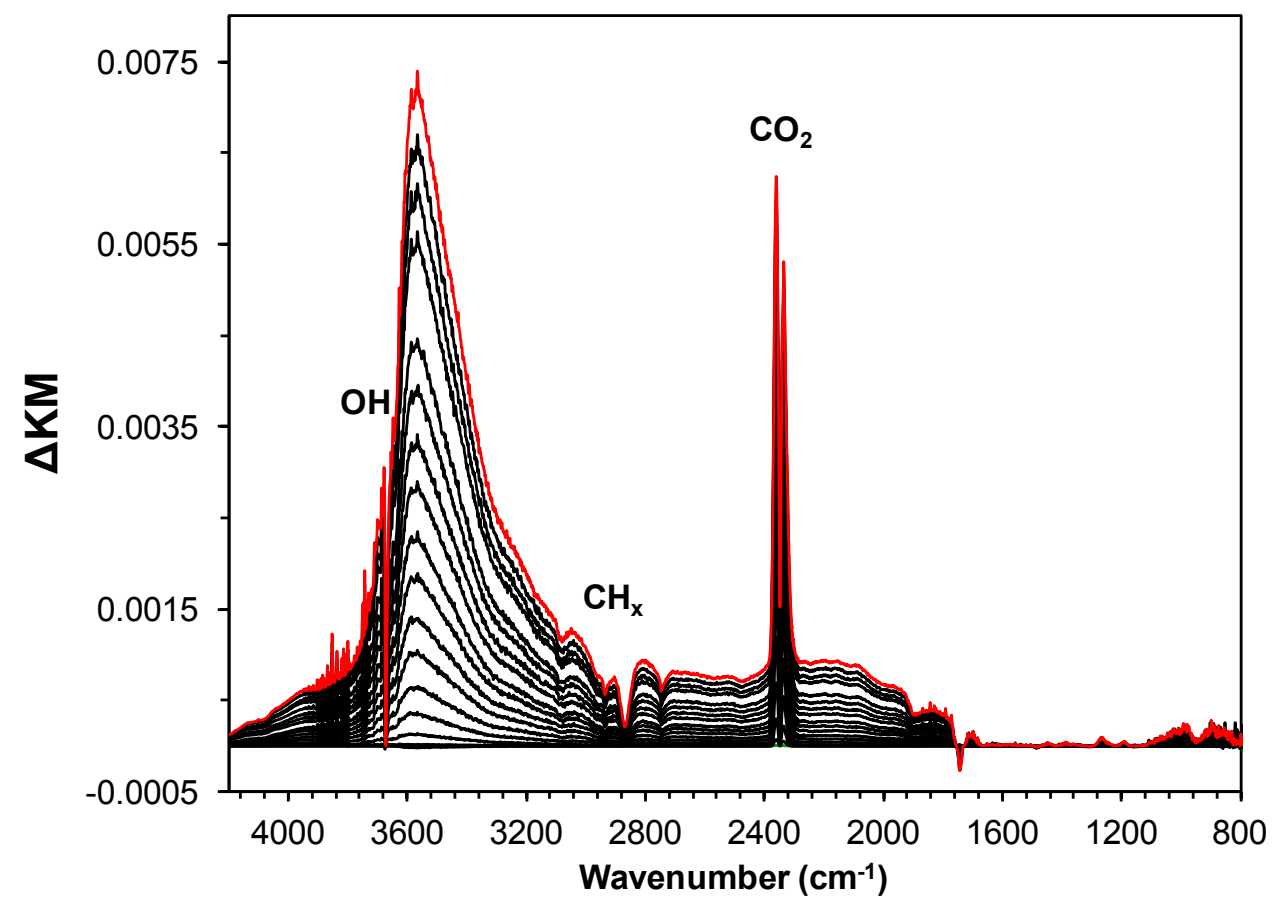

Figure S8. In situ time resolved DRIFTS data collected during dosing with $\mathrm{He}: \mathrm{CO}_{2}: \mathrm{H}_{2} \mathrm{O}$ mixture for $1 \mathrm{~h}$. 


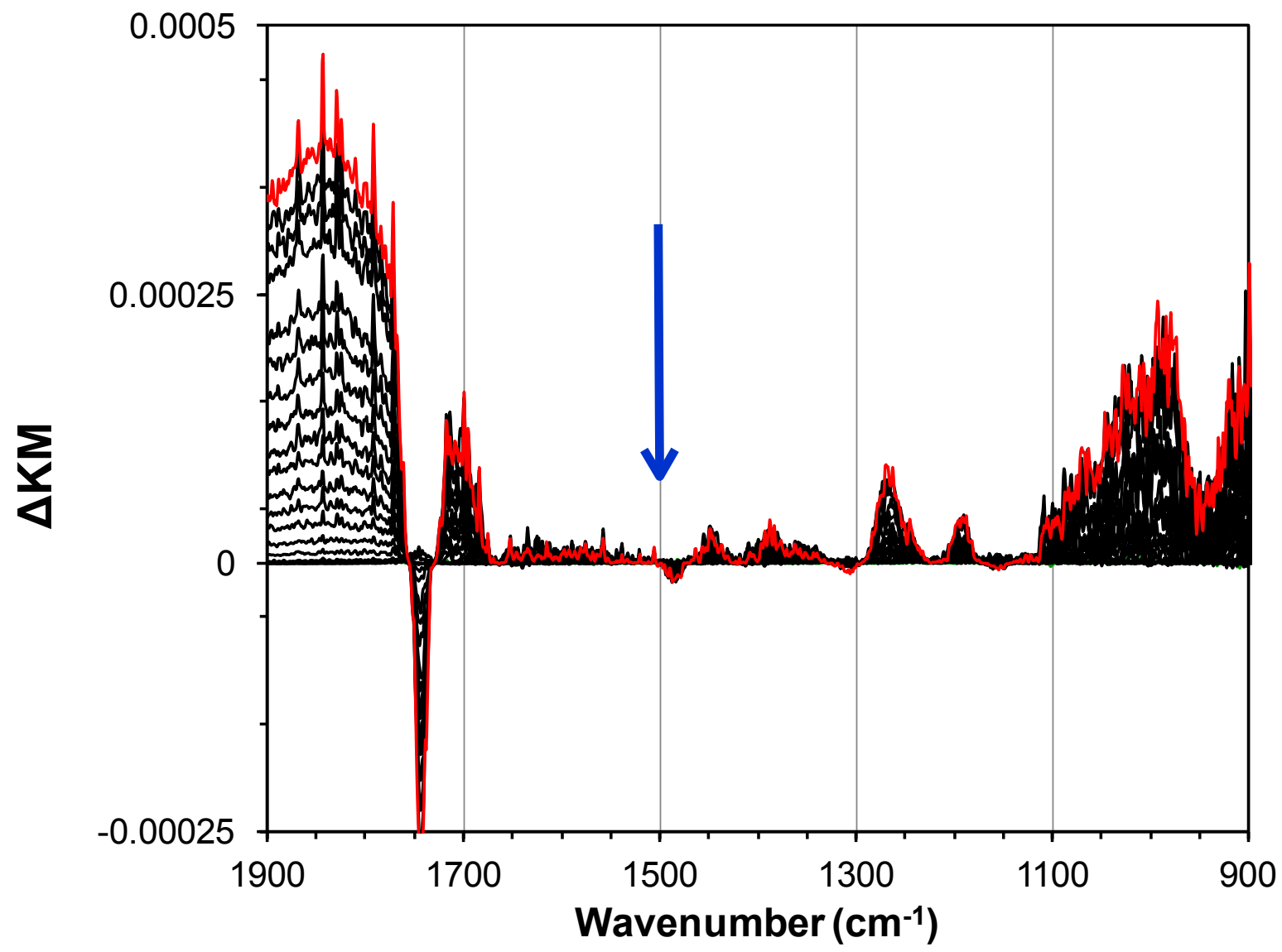

Figure S9. Fingerprint region of the in situ time resolved DRIFTS data collected during dosing with $\mathrm{He}: \mathrm{CO}_{2}: \mathrm{H}_{2} \mathrm{O}$ mixture for $1 \mathrm{~h}$. Notice the absence of $\mathrm{v}_{\text {as }} \mathrm{CO}_{3}$ peak at $\sim 1500 \mathrm{~cm}-1$ (blue arrow). 


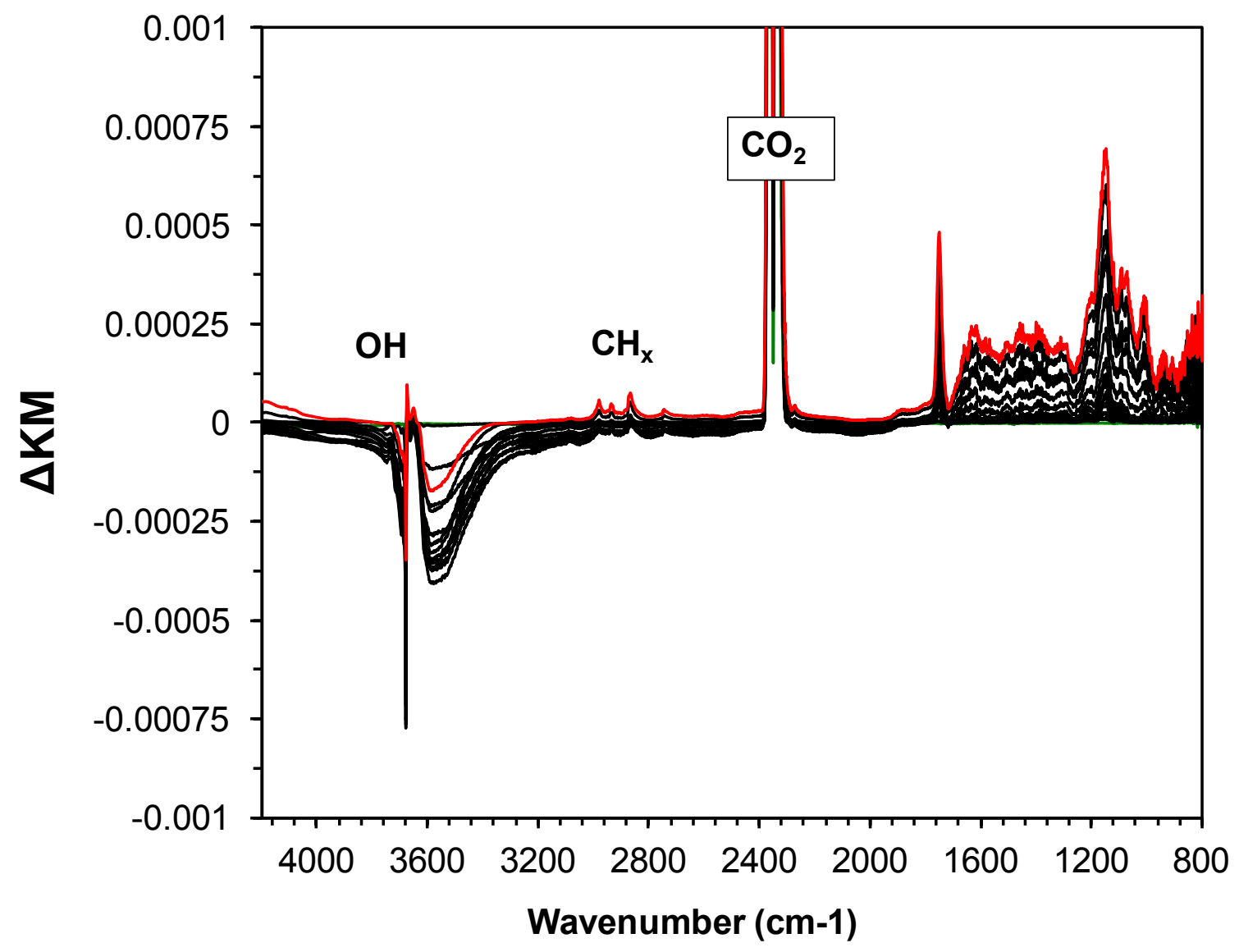

Figure S10. In situ time resolved DRIFTS data collected during dosing with $\mathrm{CO}_{2}$ for $1 \mathrm{~h}$. 


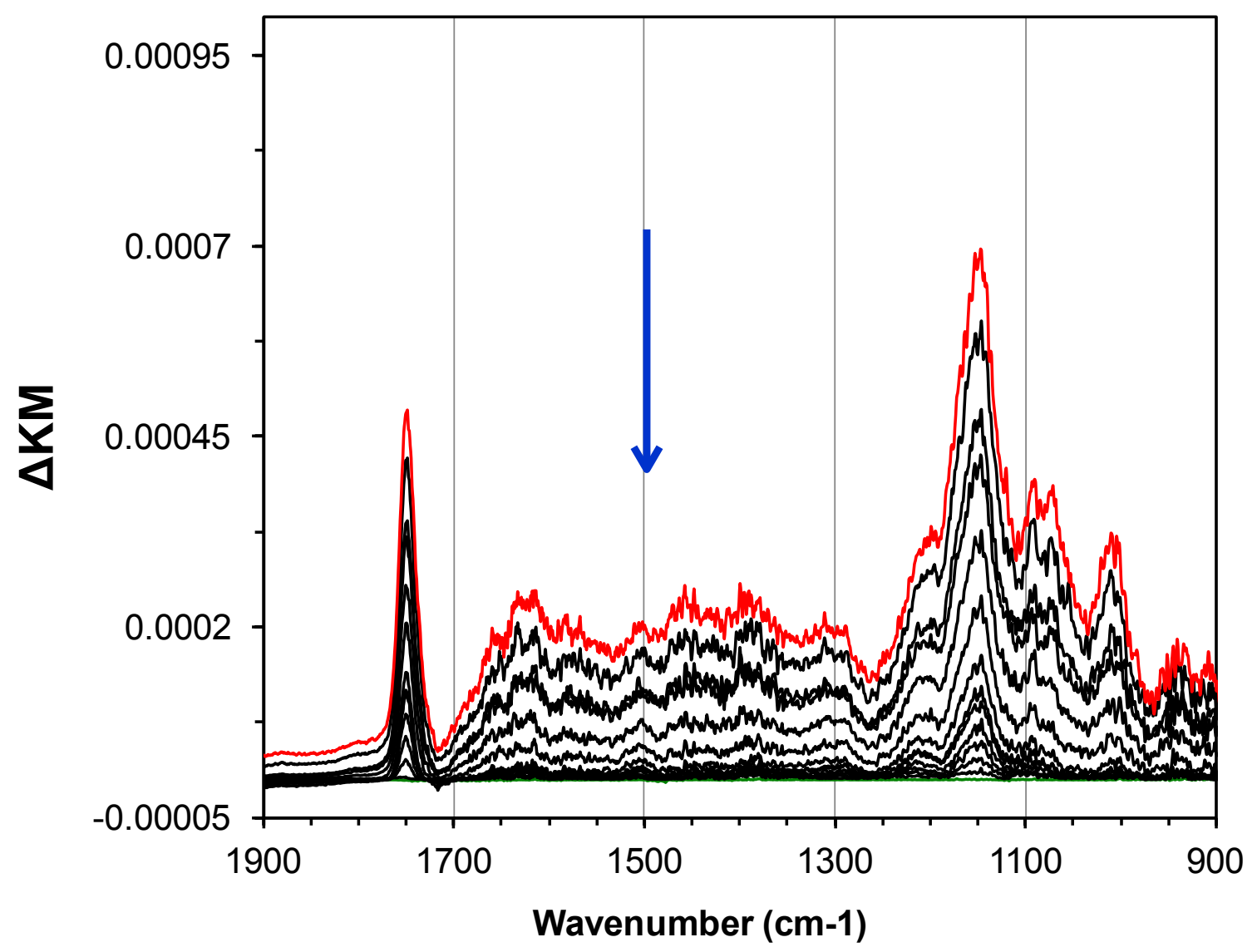

Figure S11. Fingerprint region of the in situ time resolved DRIFTS data collected during dosing with $\mathrm{CO}_{2}$ for $1 \mathrm{~h}$. Notice the absence of $v_{\mathrm{as}} \mathrm{CO}_{3}$ peak at $\sim 1500 \mathrm{~cm}-1$ (blue arrow). 


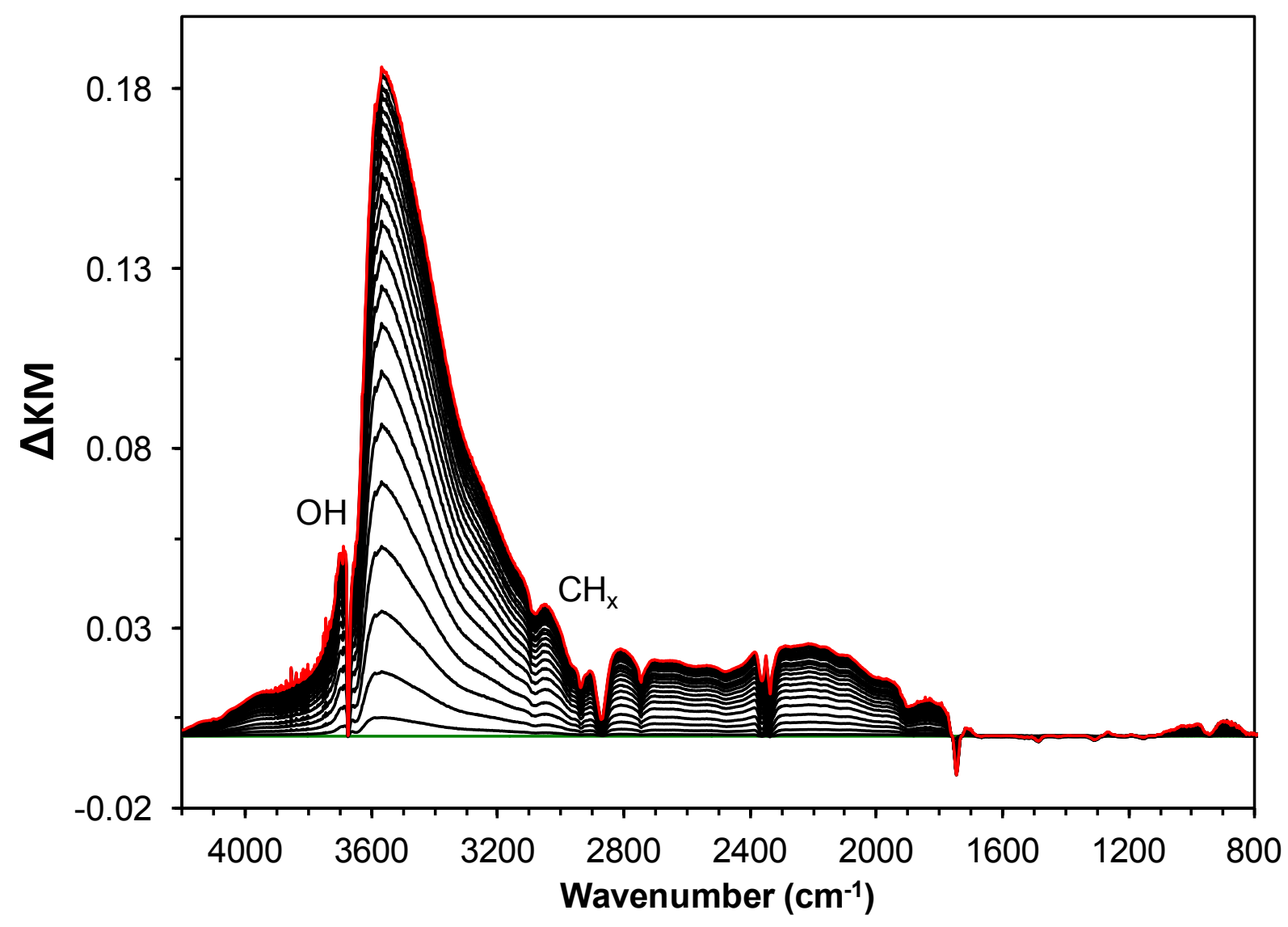

Figure S12. In situ time resolved DRIFTS data collected during dosing with $\mathrm{He}: \mathrm{H}_{2} \mathrm{O}$ mixture for $1 \mathrm{~h}$ after saturation with $\mathrm{CO}_{2}$. 


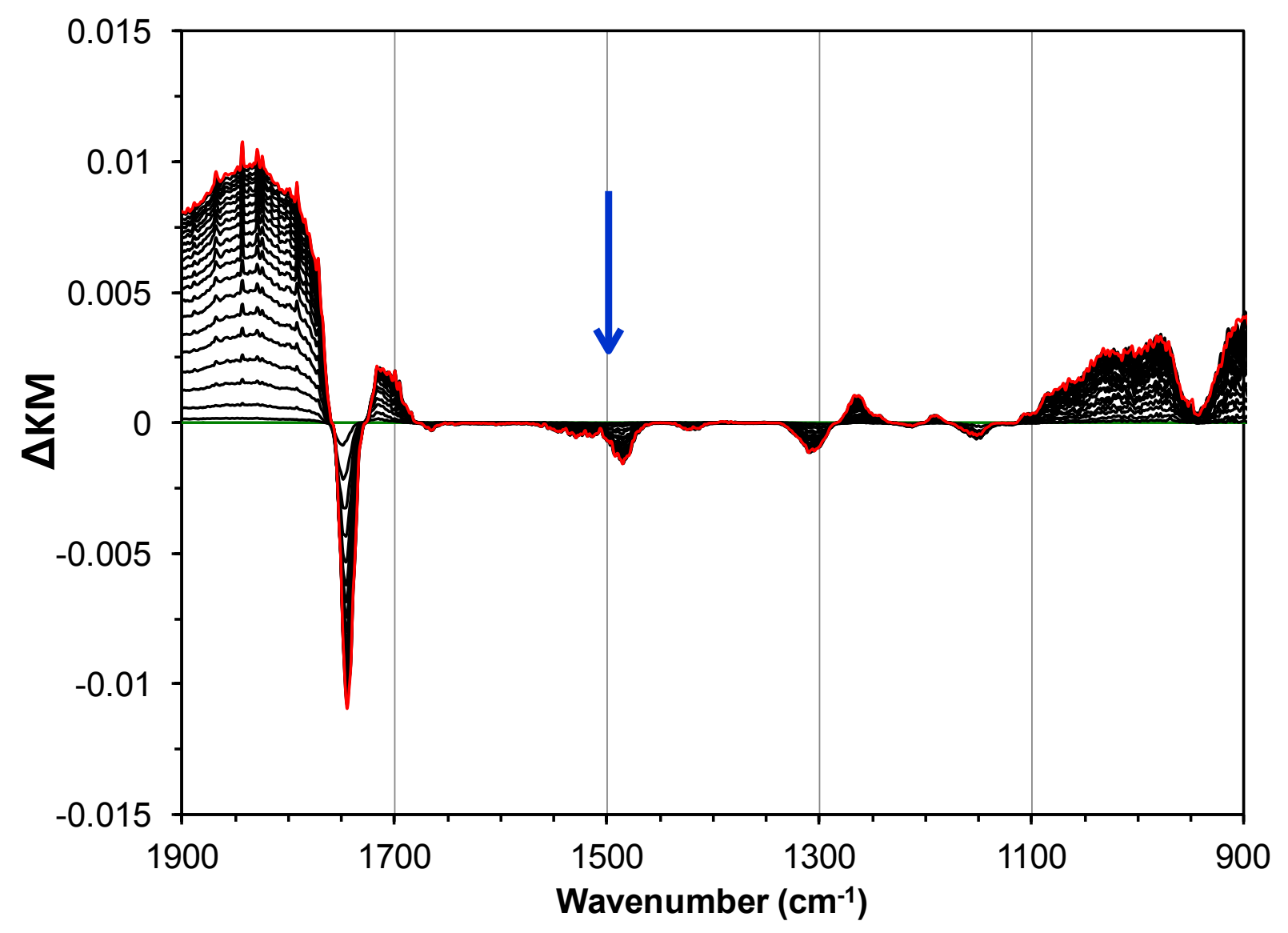

Figure S13. Fingerprint region of the in situ time resolved DRIFTS data collected during dosing with $\mathrm{He}: \mathrm{H}_{2} \mathrm{O}$ mixture for $1 \mathrm{~h}$, after saturation with $\mathrm{H}_{2} \mathrm{O}$. Notice the absence of $\mathrm{v}_{\mathrm{as}} \mathrm{CO}_{3}$ peak at $\sim 1500 \mathrm{~cm}-1$ (blue arrow). 


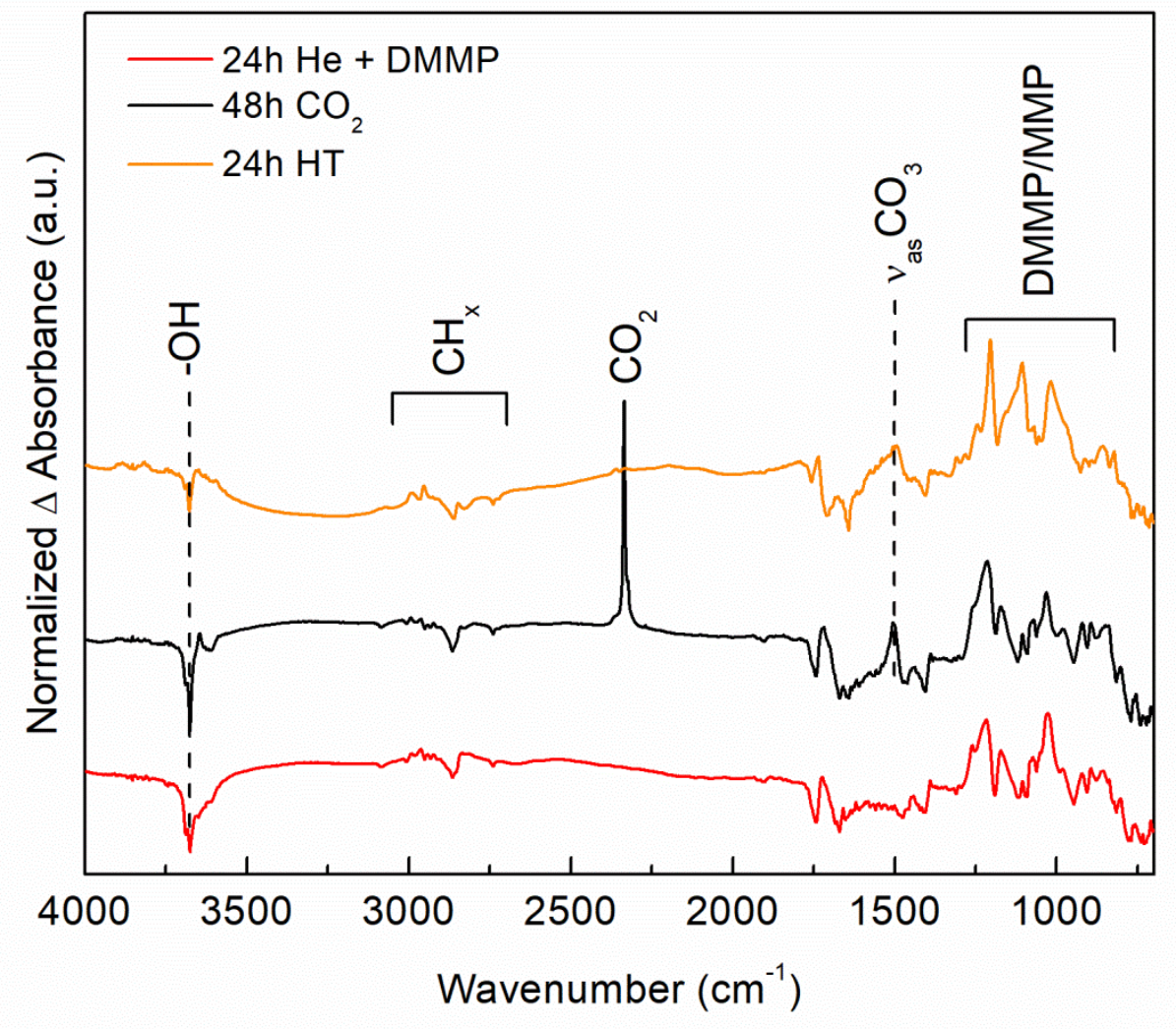

Figure S14. In situ DRIFTS experiment results, presented curves were collected in He at RT after the consequent sample treating with DMMP, $\mathrm{CO}_{2}$ and high temperature (HT; $\left.383 \mathrm{~K}\right)$. 

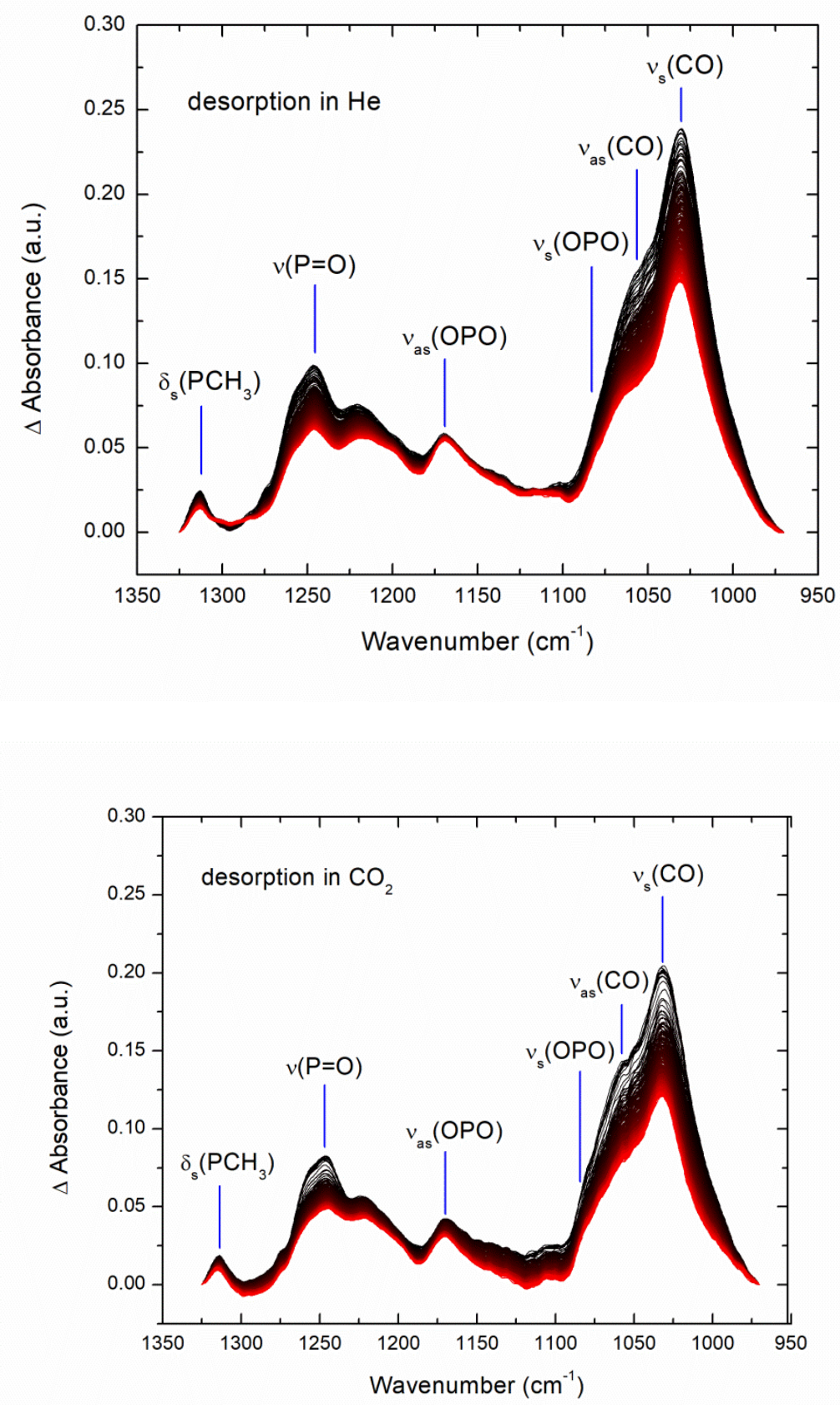

Figure S15. Background-corrected in situ difference DRIFTS spectra of the DMMP desorption experiments at RT. 


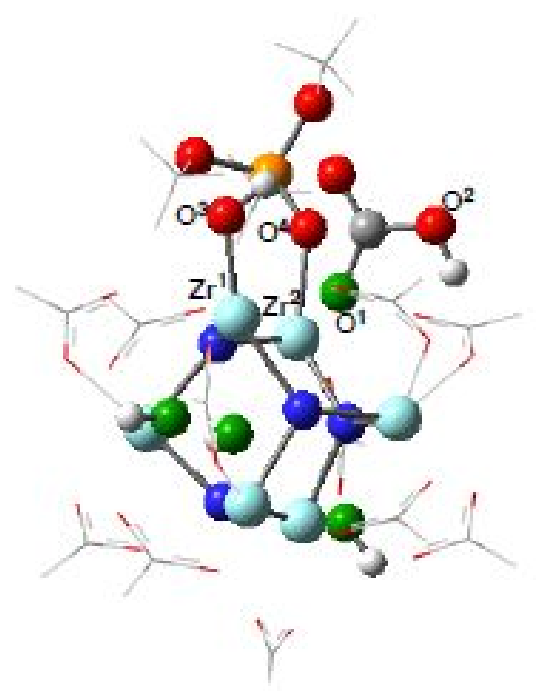

\section{$\mathrm{Zr}_{6}\left(\mu^{3}-\mathrm{O}\right)_{4}\left(\mu^{3}-\mathrm{OH}\right)_{4}\left(\mathrm{HCO}_{2}\right)_{11}(\mathrm{DMMP})\left(\mathrm{HCO}_{3}\right)$}

Figure S16. The calculated $\mathrm{HCO}_{3}$ complex of $\mathrm{Zr}_{6}\left(\mu^{3}-\mathrm{O}\right)_{4}\left(\mu^{3}-\mathrm{OH}\right)_{4}\left(\mathrm{HCO}_{2}\right)_{11}(\mathrm{DMMP})$.
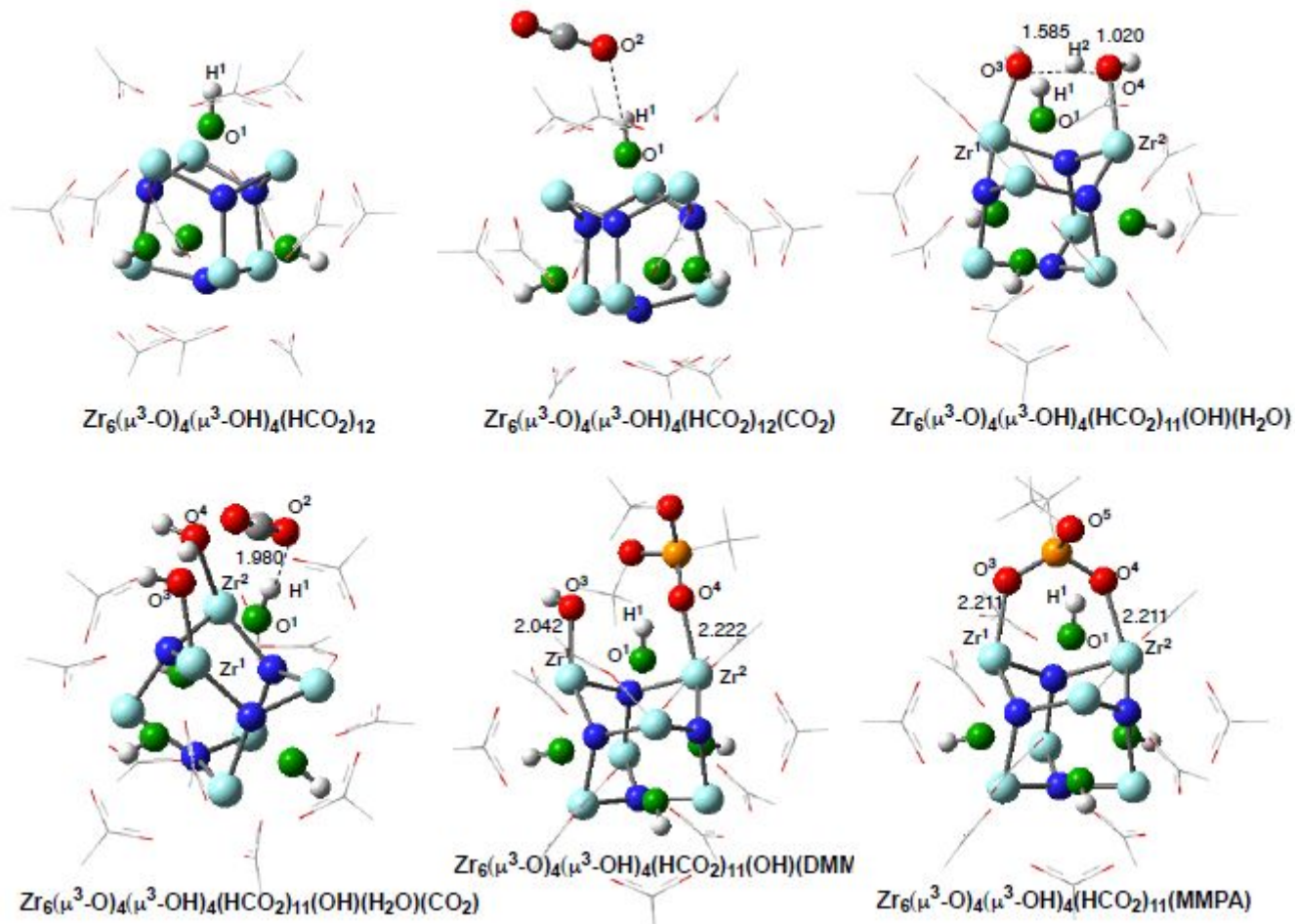

Figure S17. The calculated $\mathrm{CO}_{2}, \mathrm{H}_{2} \mathrm{O}$ and $\mathrm{H}_{2} \mathrm{CO}_{2}$ complexes of various MOF-808 model systems, which are higher in energy than those given in Figure 8. 